\title{
Exploring Policy Options in Regulating Rural-Urban Migration with a Bayesian Network: A Case Study in Kazakhstan
}

\author{
Thomas Dufhues $^{1}$ (D) $\cdot$ Gertrud Buchenrieder $^{1,2}$ (D) $\cdot$ Zhanli Sun $^{1}$ (iD
}

Published online: 8 June 2020

(c) The Author(s) 2020

\begin{abstract}
Despite the benefits associated with the free movement of people, governments often try to regulate urban immigration by constraining the agency of potential rural out-migrants in moving to cities and/or in expanding their agency to enable them to stay put. We apply an institutional framework centring on push-pull and retainrepel factors to migration intentions of potential migrants in northern Kazakhstan. We model the effects of these factors on migration intentions with Bayesian Networks and expand the baseline model with three policy scenarios. The results suggest that the effects of policies constraining urban in-migration, e.g. limiting access to affordable housing, are attenuated by social networks and reverse remittances. The supply of accessible and appropriate information on possible income and true housing costs in urban areas presents a promising road to reduce intentions of rural out-migration. Better schools and decentralised tertiary education can also reduce the migration intentions of rural residents.
\end{abstract}

Keywords Kazakhstan · Migration policies · Push-pull/retain-repel factors · Migration intentions $\cdot$ Policy scenarios $\cdot$ Bayesian networks

\section{Résumé}

En dépit des avantages associés à la libre circulation des personnes, les gouvernements tentent souvent de réguler l'immigration urbaine en limitant la capacité de potentiels

Thomas Dufhues

dufhues@yahoo.de

Gertrud Buchenrieder

gertrud.buchenrieder@unibw.de

Zhanli Sun

sun@iamo.de

1 Leibniz Institute of Agricultural Development in Transition Economies (IAMO),

Theodor-Lieser-Str.2, 06120 Halle (Saale), Germany

2 Institute of Sociology and Economics, Universität der Bundeswehr München (SOWI),

Werner-Heisenberg-Weg 39, Neubiberg, 85579 Munich, Germany 
émigrants ruraux à se déplacer vers les villes et / ou en élargissant leur capacité à rester sur place. Nous appliquons un cadre institutionnel centré sur les facteurs push-pull et les facteurs de rétention-répulsion liés aux intentions de migration de potentiels migrants dans le nord du Kazakhstan. Nous modélisons grâce aux réseaux bayésiens les effets de ces facteurs sur les intentions de migration et élargissons le modèle de référence avec trois scénarios de politiques publiques. Les résultats suggèrent que l'effet des politiques publiques limitant l'immigration urbaine, comme par exemple limiter l'accès à des logements à loyer abordable, est atténué par les réseaux sociaux et par les transferts de fonds inversés. Le fait de fournir des informations accessibles et pertinentes sur ce que l'on peut gagner, en termes de revenus, et sur ce que l'on doit dépenser pour se loger dans les zones urbaines représente une voie prometteuse pour réduire les intentions d'exode rural. De meilleures écoles et un enseignement supérieur décentralisé peuvent également réduire les intentions de migration des résidents ruraux.

\section{Introduction}

Cities that grow rapidly due to internal migration are a worldwide phenomenon. In rural areas, this has led to several well-known issues, particularly the loss of human capital, known as 'brain drain', and the over-ageing of the population (Taylor and Martin 2001). While urbanisation is a result and a driver of economic development, rapid urban immigration puts a strain on affordable housing and the provision of public goods.

To downscale rural-urban migration in the sense that fewer individuals are pulled into the city or pushed out of the countryside, governments often resort to specific legislation, regulations, and policies (i.e. exogenous institutions). These institutions intend to prevent rural residents from migrating-either by constraining the agency of potential migrants to move to cities and/or by expanding their agency to stay put. ${ }^{1}$

More authoritarian governments appear to favour laws and regulations that restrict the mobility of potential migrants. An example was the registration legislation in China or the former Soviet Union (Osmonova 2016; Yan et al. 2014). However, only the most authoritarian states, e.g. North Korea, can enforce strict mobility restrictions (de Haas 2011). Most governments, however, take a two-track approach by complementing the constraining institutions with enabling ones (Beauchemin and Schoumaker 2005). Rural development policies that focus on generating income, improving infrastructure, or on granting access to welfare enhancing public services may be implemented based on the assumption that improving the livelihoods of rural residents will enable them to stay put (Tiwari 2017).

The institutions influencing migration behaviour can be linked to Lee's (1966) well-known centrifugal push-pull factors but also to the centripetal retain-repel factors of Arango (2000). Similarly to the push-pull factors of migration, retain-repel

\footnotetext{
1 Agency is the ability of social actors to make choices in a given institutional environment (Emirbayer and Mische 1998).
} 
factors may be based on exogenous or on endogenous institutions. The analytical distinction between the centrifugal push-pull factors and the centripetal retain-repel factors has great potential to advance our knowledge regarding why some people migrate and others do not (Carling and Schewel 2018).

Therefore, the research objective of this contribution is to better understand whether and how the complex institutional environment that attempts to modify the push-pull and retain-repel factors of migration can affect migration. This is empirically depicted though the intentions of rural residents to migrate to the city. ${ }^{2} \mathrm{~A}$ better comprehension of the effects of the constraining or enabling exogenous and endogenous institutions on rural residents' migration intentions may guide governments to more effectively and efficiently tackle the issues of rural exodus and rapid population influx to cities.

Methodologically, we apply Bayesian Networks, a statistical instrument that can accommodate non-linear effects and that goes beyond the dichotomisation into dependent and independent variables in standard regression models (Anderson et al. 2004). Bayesian networks have diagnostic as well as predictive capabilities, because it is possible to conduct backward and forward inferences (Anderson and Vastag 2004). Hence, they are especially useful for exploratory and scenario analysis (Chen and Pollino 2012). After constructing a baseline model of (non-)migration, we model scenarios based on changes in the institutional environment.

To depict rural-urban migration dynamics, we chose northern Kazakhstanmore specifically, the Akmola province-as exciting case study. Nursultan is located in Akmola and, since being declared the new capital of Kazakhstan in 1997, the city has become a migration magnet. ${ }^{3}$ The highest share of incoming migrants to Nursultan originates from the surrounding mostly agrarian/rural Akmola province. Since the country's independence in 1991, the Kazakh government has been experimenting with various regulatory and policy interventions to reduce the rural exodus and to steer the internal migration flow.

\section{Institutional Arrangements on the Basis of Push-Pull and Retain- Repel Factors of (Non-)Migration}

This contribution gives attention to the question of how enabling/constraining institutional arrangements at the origin and the destination region influence the agency of (potential) migrants and how certain institutions actually work in practice (De Brauw et al. 2014). We distinguish between 'fast-moving' exogenous institutions, e.g. targeted policies, which can be quickly and deliberately changed by way of a

\footnotetext{
2 The use of intentions to proxy actual migration behaviour is widely accepted, both theoretically and methodologically (de Jong 2000).

3 In March 2019, Kazakhstan's capital city was renamed Nursultan to honour the former president Nursultan Nazarbayev. When the city became the new capital in 1997, its name was changed from Tselinograd to Astana.
} 
centralised political process, and 'slow-moving' endogenous institutions, e.g. norms (Roland 2004).

Arango (2000, p. 293) states that "theories of migration should not only look to mobility but also to immobility, not only to centrifugal forces but also to centripetal ones". Centrifugal forces are associated with the famous push-pull model of Lee (1966). It is based in the neoclassical economics paradigm. As Massey et al. (1998) point out, individual (im)mobility in the neoclassical model is the result of decisions made by rational actors who evaluate the costs and benefits of moving relative to staying. Nevertheless, the push-pull model of migration is criticised on multiple fronts (Schewel 2019): for ignoring migrant agency (de Haas, 2011), for overlooking the influence of more intangible forces like culture and norms (Schewel 2015), but also for neglecting the government and politics (Hollifield 2008). Yet, as (Davis 1988) puts it, (non-)migration is a creature of national and/or international regulation and policy.

Centripetal forces are associated with retain-repel factors and may either facilitate staying or discourage migration (Arango 2000). Schewel (2019) describes retain factors as attractive conditions at home that bolster the aspiration and/or capability to stay, e.g. social ties, job opportunities, or the provision of public goods. Public interventions in retain factors aim at creating equivalent living conditions in rural regions as compared to urban ones. Repel factors relate to conditions elsewhere, e.g. in the urban destination. They include negative perceptions of economic, cultural, and political dimensions of the migration process and the imagined destination, ranging from the prospect of unemployment (Todaro 1969), language barriers (Buchenrieder et al. 2019), to political barriers to movement (Arango 2000). Schewel (2019) emphasises that the nature and functioning of repel factors have received less attention than retain factors in explaining (non-)migration.

Our comparative institutional analysis framework approaches (non-)migration from two perspectives: Exogenous and endogenous institutions may (1) push emigrants from origin areas and/or pull immigrants into destination areas and they may (2) retain residents in their origin area and/or repel migrants from destination areas.

\section{The Institutional Environment of Rural-Urban Migration in Kazakhstan}

As there had never previously been a Kazakh nation state (except for a few years in the 1920s), the Kazakh government's most important task following the collapse of the Soviet Union and independence in 1991 was to establish a concept of nationhood. The government followed two main strategies. The first was to increase the ethnic Kazakh population above 50\%, because Kazakhstan was the only successor state of the Soviet Union whose titular group was an ethnic minority (Schatz 2000). The government did not stop the emigration of Russians and other minorities from its territory while, at the same time, promoted the immigration of ethnic Kazakhs from abroad (Alff 2010). The population composition has since then changed such 
that Kazakhs are now the majority. ${ }^{4}$ But these events did not prove sufficient to correct for regional ethnic imbalances. Thus, the change in population composition was accompanied by a second political strategy: the promotion of internal migration into the northern regions, where traditionally Kazakhs had been a minority. In this regard the relocation of the capital from Almaty to Nursultan in the northern Akmola province was central.

The government justified the relocation by claiming that Nursultan would serve as a focal point for regional economic growth (Anacker 2004). Furthermore, the Soviet narrative of cities as the cradle of modern amenities and economic progress is kept alive and is reflected, e.g. in propagating Nursultan as a modern metropolis (Alexander et al. 2007). As regards the general transformation process of a planned to a market-oriented economy in Kazakhstan, urban areas have profited more from economic growth than rural areas (Alff 2010). Urban economic growth is associated with a boom in the job market, leading to comparably high salaries. Also, cities usually offer a range of amenities which relate to the better endowment with public goods such as educational, health, and cultural facilities. These political and economic factors pulled people from the Kazakh countryside towards urban centres.

Public investment in urban public goods could not keep pace, however, with the rising urban population and Kazakh policy makers became very concerned about negative side effects of the migrant influx into major cities, i.e. into Nursultan and Almaty (An et al. 2017). Thus, the City Planning Department of Nursultan, for instance, started to more tightly control construction planning, to ration the designation of building land and building permits. These restrictions on the building of new houses and apartments have forced up housing prices. Consequently, the wage surplus paid in the city compared to the surrounding countryside is devoured by the high rents. This was, according to city officials, a wanted effect to repel rural-urban migration. As a reaction to the constrained housing situation, many unsuccessful apartment seekers call upon their extended family network to find a place to stay and/or financial support (Dietz et al. 2011). The endogenous social network serves thus to circumvent the regulatory agency of Nursultan City Planning Department with regard to rationing the housing market. While the social networks in the city may not necessarily pull rural migrant, they reduce the repel forces.

The collapse of the Soviet education system in the 1990s left only the large centralised education facilities in the cities intact (Toleubayev et al. 2010). Some of these have been further supplemented by newly built facilities that also offer study programmes in crafts and trades. The number of colleges in rural areas, however, was dramatically reduced (OECD 2007). As a result, young adults from rural areas in search of higher education were pushed out of rural areas. Once in the city, they often stayed as they grew accustomed to city amenities and loosened their social bonds to their home region. This migration behaviour is known as the 'migrating-tolearn' - 'learning-to-migrate' chain (Rérat 2016).

\footnotetext{
4 Today ethnic Kazakhs are the majority (63\%) and ethnic Russians a minority (24\%) (Abdramanova 2017; Peyrouse 2007).
} 
In response to the over-ageing and lack of human capital in rural Kazakhstan, special policy measures ${ }^{5}$ aiming at rural regional development were set up to slow down rural-urban migration, in other words retain rural people. Furthermore, special public scholarship programmes were launched to retain qualified personnel in rural areas. Young rural adults can receive a scholarship to study a professional field that is in demand by state agencies in rural areas. Furthermore, in a nationwide effort to attract urban graduates to rural areas, the government offers higher salaries and subsidised housing. Participants of these programmes are required to work 5 years for state agencies in rural areas (GovReKaz 2018).

Furthermore, decentralised education facilities have been established in more recent times. In the Akmola province, this has led to the opening of colleges in regional towns. Thus, young adults do not have to leave their home region for higher education. The decentralisation of education facilities is also expected to create local jobs, e.g. in the service sector, and attract new businesses. By making the conditions at home more attractive, these retain factors bolster the preference to stay.

\section{Sample and Description of Variables}

\section{Sample}

The field work in the Akmola province, Kazakhstan took place in 2016/2017. We applied a mixed method survey design to combine the strengths of quantitative and qualitative data collection methods. For the quantitative household survey, a random sample of 400 rural households was drawn in the area of Akmola.

We followed a three-stage clustered sampling procedure. The province consists of 17 districts (plus two urban regions). First, we excluded the four districts that are within commuting distance of Nursultan and the provincial capital, Kokshetau. Then we randomly drew seven of the remaining 13 rural districts. Second, we picked six villages at random within each district. Third, a random route sampling for the households was applied in the villages. In each village, ten households were randomly selected (except for four comparatively small villages of just above 50 households where only five households were sampled). Within the households, the person between the ages of 16-50 who had most recently celebrated a birthday prior to the interview date was interviewed. In these interviews, relevant data on all adults and the general socio-economic situation of the household were collected. We excluded 45 interviews from the analysis. Interviews were not considered if the respondents planned to move to another rural area or to an international destination, or if the respondent could not give an estimation of the likelihood of moving to a Kazakh city. Furthermore, we conducted qualitative interviews with 28 potential migrants,

\footnotetext{
5 The policy measures we refer to are, e.g. the Agriculture and Food Program, the Agribusiness 2020 Program, and the Road Map for Social Development or moving state agencies into rural areas to create jobs.
} 
Table 1 Target variable: intention to migrate

\begin{tabular}{lc}
\hline & $\begin{array}{l}\text { Number of } \\
\text { respond- } \\
\text { ents }\end{array}$ \\
\hline $\begin{array}{l}\text { 0= very low or no intention to move (Likert scale } \\
\text { values 0, 1) }\end{array}$ & 274 \\
$\begin{array}{l}1=\text { intention to move (Likert scale values 2-10) } \\
\text { Total }\end{array}$ & 81 \\
\hline
\end{tabular}

38 actual migrants in Nursultan, Kokshetau, and few smaller cities in Akmola, 25 government officials/experts at regional and national levels and 41 semi-structured interviews with village leaders.

\section{Variable Description}

Our main variable of interest is the migration intention of villagers. We asked respondents whether they would move to an urban location in another district in Kazakhstan within the next three years. Respondents answered on a Likert scale from zero to ten, where zero translates into a zero probability of moving (i.e. definitively staying) and ten means a $100 \%$ probability of moving. We discretised the answers into two states. As shown in Table 1, some three quarters of our respondents have no migration intention, which is not surprising as the vast majority of people worldwide remains immobile.

In the following, we describe the reasoning behind the selection of the variables for the Bayesian Network. The description of the variables and their measurement can be found in Appendix Table 5. The variables are clustered into five major themes, which came out of the literature review and qualitative research: (1) assessment of the urban option, (2) peer issues, (3) psychological stress, (4) assessment of public goods and job market, and (5) opportunities for children and young adults.

\section{Assessment of the Urban Option}

Better education is perceived to increase the expected benefits from migration, particularly when entering the job market (Taylor and Martin 2001). Unlike during the Soviet era, employment in civil services now requires an excellent knowledge of the Kazakh language (Schatz 2000). This qualification is growing more important in the private sector too (Bissenova 2017; Peyrouse 2007; Wolfel 2002). Therefore, individuals with a good command of Kazakh have a higher probability of finding a job in the city; up to now these are primarily ethnic Kazakhs. Non-Kazakh ethnicities, e.g. ethnic Russians, rarely master the Kazakh language satisfactorily (Aitymbetov et al. 2015).

Migration networks can lower the cost of migration, both financially and psychologically (De Brauw et al. 2014). According to Dietz et al. (2011), about $40 \%$ of the migrants they surveyed financed their move primarily through family networks. However, our qualitative interviews have shown that direct migration costs, 
in terms of transport costs to urban areas, seem to be irrelevant. Hence, migration costs are mostly related to accommodation in the urban location and to overcoming the interim period while searching for a job.

Personal character traits influence the assessment of the perceived costs and benefits and, consequently, the intention to migrate (Carling 2002). Empirical evidence suggests that migrants are substantially less risk-averse than stayers (Jaeger et al. 2010). This, of course, influences the migration intention of potential migrants.

The household's general income situation has a clear influence on migration capability. On the one end, rural high-end income households usually do not need to move to urban areas. On the other end, poor households are often unable to finance the relocation and bridge the time without income while searching for a new job. Usually the middle income households have the desire to increase their income and the ability to finance the move.

\section{Peer Issues}

Community or family norms and opinions are important determinants of whether migration is considered appropriate. Subsequently, peer issues are expected to be one of the major factors in the formation of the intention to migrate or not (de Jong 2000). They can go both ways, migration may be considered a way of life (push factor) or staying put may be socially expected (retain factor).

\section{Psychological Stress}

Emotional identification with the home region is a retain factor and influences migration intentions (Thissen et al. 2010). During the qualitative research phase, the visited villages showed a low level of civic involvement. Furthermore, collective leisure time activities, e.g. sport clubs were found to be non-existent. Cultural activities in rural areas were largely missing while they exist in ample number in urban areas. Therefore, we believe that the most important factor defining local attachment is the individual attitude towards the typical facets of the rural way of life (e.g. quietness, beautiful nature, close contact to neighbours, etc.).

Social bonds at the place of origin are part of the psychological cost-benefit consideration of a potential migrant. Strong social bonds can reduce the intention to migrate (Alesina and Giuliano 2010). Furthermore, leaving may become impossible if family members need special care. The life-cycle of potential migrants is also important, specifically if the potential migrant is married (Abraham and Nisic 2012). These are possible retain factors.

\section{Assessment of Rural Public Goods and Job Market}

The state of rural public goods influences migration intentions. To this extent, governments can create incentives to stay by providing missing and improving existing public goods, e.g. improved rural health care or education (Castles 2004). A better endowment with public goods also influences the job market, which is primarily 
agricultural. In Akmola, family farms are scarce and people usually work as employees in big agro-holdings (Petrick et al. 2013).

\section{Opportunities for Children and Young Adults}

Access to good schools and higher education facilities are important factors influencing migration decisions, especially for families with children or young adults. This may be particularly valid for people who are low on the income ladder. They may see education as an escape from poverty, but do not have the financial means to send their children away for (boarded) schooling. Soviet style development opportunities for children (e.g. the local chess club) exist in urban centres and are often mentioned as missing in the village. Additionally, interviewees emphasised the concentration of political institutions in Nursultan. Being close to these centres of power is seen as desirable for their children's future.

\section{Constructing a Bayesian Network}

A Bayesian Network is a directed acyclic graph that represents the variables and their quantified relationships using Bayes' probability theory (Jensen 2001). Variables are linked with directed arrows to illustrate the statistical interdependence. The relationships between input variables and their dependent variables are usually quantified by conditional probability tables (CPTs) (Zorrilla et al. 2010). CPTs define the probability distributions of variables conditioned upon the values of their input variables (where an arrow originates, see Fig. 1) (Frayer et al. 2014). The CPTs for each variable with input variables are learnt from the household data using the expectation maximisation (EM) algorithm within the Netica software.

As Bayesian Networks consist of a graphic structure and CPTs, the development of a Bayesian Network entails a two-step procedure. The first step is to induce the structure of the directed acyclic graphs. The second step estimates the parameters, i.e. the CPTs, of the Bayesian Network based on the structure developed in step one (Kjaerulff and Madsen 2013). The development of the structure often involves the creation of an influence diagram (Marcot et al. 2006). The influence diagram is used as a conceptual model for structuring the problem and determining direct correlations. A central advantage of Bayesian Networks is that the structure of the associated influence diagram determines the dependence and independence among the variables (Aguilera et al. 2011).

Still, giving Bayesian Networks the appropriate structure is a challenging issue. While in theory the structure can be learnt from data through a data mining and learning procedure, the learnt structure may not reflect the true causal relationships as the learning algorithm is based on statistical correlations. These do not always translate into causal relationships. To account for this challenge, we also adhered to insights from relevant literature, consultations with local experts, and discussions with villagers and migrants to develop the network structure and the selection of variables. Variables in Bayesian Networks are usually discrete variables; each 


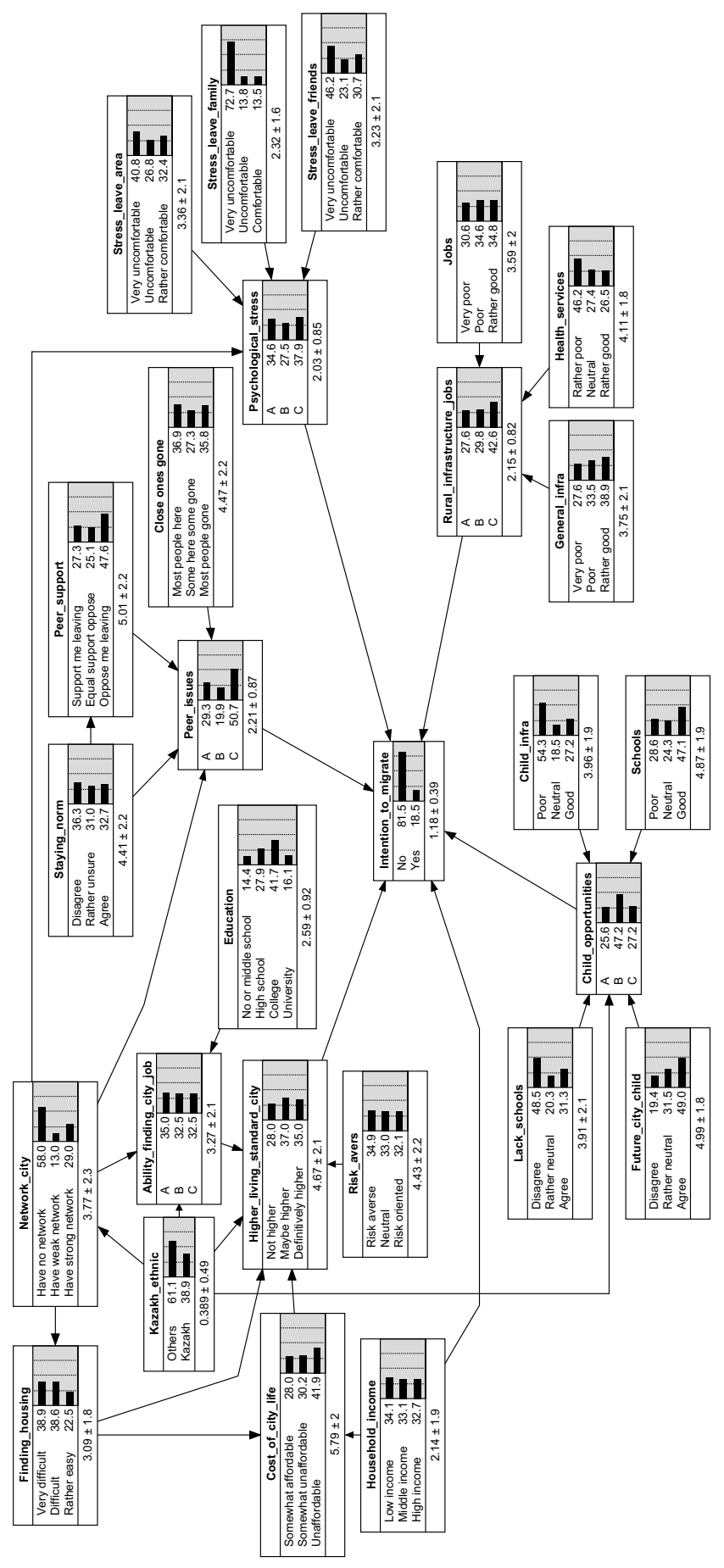

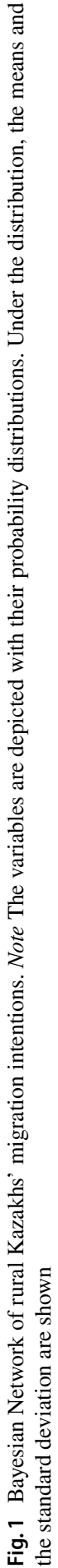

称 
variable is described by a set of mutually exclusive states. In this context, we had to discretise continuous variables into a finite set of states (e.g. $<5,5-10,>10$ ) (Chen and Pollino 2012) (see Appendix Table 5).

One of the principles in the design of the Bayesian Network is to keep the network parsimonious - especially when working with a small dataset. The number of input variables to any variable should be kept at a minimum and the number of their states should, as a rule of thumb, not exceed five. This keeps their CPTs small enough to be tractable and understandable. ${ }^{6}$ Moreover, the depth of the Bayesian Network, which means the number of layers of variables, should not exceed four, because, e.g. the sensitivity of the outcome variable to input variables may be dampened by the intermediate variables (Marcot et al. 2006). The strength of the relationships between variables is depicted in the CPTs of each variable (Chen and Pollino 2012).

\section{Results and Discussion}

A number of variables, which were a priori hypothesised to be important (see Sect. 4.1), were later excluded because they carried redundant information and/ or had relatively low explanatory power. Variables were kept in the Bayesian Network if the error rate remained stable or decreased and if their influence on the target variable, migration intention, was above $0.05 \%$ variance reduction. After removing ten variables with low influence from the Bayesian Network, the desired compromise between simplicity and high model accuracy, measured by the error rate, was achieved (Frayer et al. 2014). The baseline model (see Fig. 1) contains 21 variables and five latent variables.

\section{Sensitivity and Diagnostic Analysis}

We conducted a sensitivity analysis to quantify the influence of each variable on our target variable: the migration intention. This analysis describes how sensitive the Bayesian Network behaves by determining the changes in probabilities of certain variables to changes in inputs of other variables (Pollino et al. 2007). As our Bayesian Network is populated with discrete and categorical variables. We employ entropy reduction calculations. Within the sensitivity analysis, input variables are rank-ordered and compared quantitatively to the degree to which each input variable reduces the entropy in the outcome variable. Thus, sensitivity analysis determines the input variables with the highest influence on the outcome variable (Chen and Pollino 2012; Marcot 2012).

\footnotetext{
6 An approach to keep CPTs small is through 'divorcing' variables. Here a few variables are aggregated into a summary latent variable (Chen and Pollino 2012). We used this approach to create the latent summary variables: 'ability finding city job', 'peer issues', 'psychological stress', 'assessment of rural infrastructure/jobs (public goods and job market), and 'opportunities for children'.
} 
Table 2 Sensitivity analysis

\begin{tabular}{|c|c|c|}
\hline \multirow[t]{2}{*}{ Variables } & \multicolumn{2}{|l|}{ Variance reduction $(\%)$} \\
\hline & $\begin{array}{l}\text { On target variable (migration } \\
\text { intention) }\end{array}$ & $\begin{array}{l}\text { On sum- } \\
\text { mary vari- } \\
\text { ables }\end{array}$ \\
\hline Peer issues (summary/latent variable) & 16.8 & \\
\hline Peer support & 4.3 & 15.7 \\
\hline Staying norm & 3.2 & 10.2 \\
\hline Network city & 1.3 & 2.4 \\
\hline Close ones gone & - & 1.6 \\
\hline Higher living standard (summary variable) & 11.9 & \\
\hline Cost of city life & 1.2 & 7.9 \\
\hline Finding housing & 0.9 & 4.5 \\
\hline Kazakh ethnic & 0.8 & 1.0 \\
\hline Ability finding city job & - & 1.0 \\
\hline Child opportunities (summary/latent variable) & 5.5 & \\
\hline Schools & - & 2.9 \\
\hline Lack schools & - & 2.1 \\
\hline Future child city & - & 1.5 \\
\hline Kazakh ethnic & (see above) & 1.2 \\
\hline
\end{tabular}

Only variables with a variance reduction greater than $0.5 \%$ are shown. The right-hand side column shows three different sensitivity analyses, one for each summary variable

We follow Frayer et al. (2014) who discuss only variables with a variance reduction greater than $0.5 \%$, because they are viewed as having major effects on the target variable. Table 2 shows the results of the sensitivity analysis. The variables are ranked in descending order of influence on the target variable. We also conducted a sensitivity analysis for influential summary variables (specifically 'peer issues', 'higher living standard', and 'child opportunities') to detect which input variable has the biggest influence on these summary variables. The summary variables 'psychological stress' and 'rural infrastructure' only had minor effects on the target variable and are therefore not presented.

In relation to the sensitivity analysis, we investigate the strength of the interactions between our target variable 'migration intention' and the influencing variables with a diagnostic analysis. The diagnostic analysis uses the two-way inference capability of Bayesian Networks. It estimates how the probabilities of influencing variables change given evidence in the target variable, which, in our binary variable, is (1) having a 'migration intention' and (2) having 'no migration intention'. Similar to the sensitivity analysis, we explore only variables with a variance reduction greater than $0.5 \%$ (see Table 3). Furthermore, we refrain from investigating the effects on the two summary variables 'peer issues' and 'child opportunities' because they are latent variables and have been constructed by Netica. Table 3 shows the initial state of probability distributions, taken from Fig. 1 and the changes in the probabilities 
Table 3 Diagnostic analysis

\begin{tabular}{|c|c|c|c|c|}
\hline \multirow[t]{2}{*}{ Variables } & \multirow[t]{2}{*}{ States } & \multirow[t]{2}{*}{ Initial state } & \multicolumn{2}{|c|}{ Changes of states (\%) } \\
\hline & & & $\begin{array}{l}\text { No migra- } \\
\text { tion inten- } \\
\text { tion }\end{array}$ & Migration intention \\
\hline \multirow[t]{3}{*}{ Peer support } & Majority support leaving & 27.3 & -4.4 & 23.9 \\
\hline & Equal support/oppose & 25.1 & 1.1 & -6.0 \\
\hline & Majority oppose leaving & 47.6 & 3.3 & -17.9 \\
\hline \multirow[t]{3}{*}{ Staying norm } & No & 36.3 & -3.9 & 21.3 \\
\hline & Neutral & 31.0 & 1.2 & -6.6 \\
\hline & Yes & 32.7 & 2.7 & -14.8 \\
\hline \multirow[t]{3}{*}{ Network city } & No network & 58.0 & 2.5 & -13.4 \\
\hline & Weak network & 13.0 & -0.2 & 0.8 \\
\hline & Strong network & 29.0 & -2.3 & 12.6 \\
\hline \multirow[t]{3}{*}{ Close ones gone } & Most here & 36.9 & 1.2 & -6.5 \\
\hline & Some here/some gone & 27.3 & -0.2 & 1.1 \\
\hline & Most gone & 35.8 & -1.0 & 5.4 \\
\hline \multirow[t]{3}{*}{ Higher living standard } & Not higher & 31.9 & 3.9 & -20.7 \\
\hline & Maybe higher & 40.9 & 3.9 & -21.5 \\
\hline & Higher & 27.2 & -7.8 & 42.2 \\
\hline \multirow[t]{3}{*}{ Cost of city life } & Affordable & 25.8 & -2.2 & 11.8 \\
\hline & Somewhat unaffordable & 30.4 & 0.2 & -1.2 \\
\hline & Unaffordable & 43.8 & 1.9 & -10.7 \\
\hline \multirow[t]{3}{*}{ Finding housing } & Very difficult & 40.7 & 1.8 & -9.7 \\
\hline & Difficult & 38.4 & -0.2 & 1.3 \\
\hline & Rather easy & 21.0 & -1.5 & 8.3 \\
\hline \multirow[t]{2}{*}{ Kazakh ethnicity } & Others & 63.2 & 2.1 & -11.1 \\
\hline & Kazakh & 36.8 & -2.1 & 11.1 \\
\hline \multirow[t]{3}{*}{ Schools } & Poor & 27.5 & -1.1 & 5.9 \\
\hline & Neutral & 24.8 & 0.5 & -2.8 \\
\hline & Good & 47.7 & 0.6 & -3.0 \\
\hline \multirow[t]{3}{*}{ Lack schools } & Disagree & 49.2 & 0.7 & -4.1 \\
\hline & Rather neutral & 20.5 & 0.2 & -1.2 \\
\hline & Agree & 30.3 & -1.0 & 5.3 \\
\hline \multirow[t]{3}{*}{ Future child city } & Disagree & 19.1 & -0.3 & 1.8 \\
\hline & Rather neutral & 32.0 & 0.5 & -2.5 \\
\hline & Agree & 48.9 & -0.1 & 0.7 \\
\hline
\end{tabular}

Only variables with a variance reduction greater than $0.5 \%$ are shown. Therefore, the two latent summary variables 'peer issues' and 'child opportunities' are not shown

of the influencing variables when the migration intention falls into a specific state (intention/no intention). The magnitude of the probability changes then resembles the strength of the influence (Frayer et al. 2014). 


\section{Peer Issues}

Interestingly, the latent variable 'peer issues', which is a proxy for an endogenous institution in the form of social norms and networks, has the strongest influence on the intention to migrate. The effect of peers is based on normative factors and instrumental support through family, friends, and social networks (e.g. finding housing, jobs, and receiving moral support). This result is likely linked to the observed strong family bonds in Kazakhstan and the resulting acceptance of related norms. It is also reflected in the fact that two thirds of the respondents stated that migration decisions are not purely individual decisions, but are made jointly within the household. In collectivistic cultures, such as the Kazakh culture, people tend to pick up signals on appropriate behaviour from groups (Hofstede 2001), which also increases norm compliance.

\section{Assessment of the Urban Option}

The variable with the second highest influence on the migration intention is the assessment of the urban option. This is the respondent's evaluation of whether or not it is possible to achieve a higher living standard in an urban area compared to his/her rural location. The variables 'cost of city life' and 'finding affordable housing' have a higher influence on this assessment than the variable 'finding city job'. During our qualitative interviews, most respondents stated that the job markets in the cities, and especially in Nursultan, offer many opportunities for well-paid jobs. Rural-urban wage differentials thus appear to constitute a pull factor. Nevertheless, this assessment seems to be overly optimistic as Dietz et al. (2011) state that many migrants in Nursultan report their income to be the same or even less than prior to migration. The wage surplus paid in the city compared to the surrounding countryside is often devoured by the high housing costs (OECD 2017). As a counterbalance to the high housing costs, the government has set up subsidised housing programmes for civil servants and public employees (Bissenova 2017). However, the process from application to allocation of a subsidised apartment can last years. It should be noted that these programmes indirectly discriminate against ethnic non-Kazakhs (mostly Russians) as they have a much smaller chance of finding state employment due to languages barriers. Not surprisingly, the administration is now dominated by ethnic Kazakhs (Wolfel 2002). Thus, ethnicity affects chances in the urban job market and influences migration intentions in such a way that ethnic Russians tend to remain in rural areas more often. The need to be able to command Kazakh functions as a repel factor for ethnic Russians seeking to work in urban areas.

As pointed out earlier, the extended family network may provide accommodation at expensive city locations or provides financial support. Instead of receiving remittances from urban migrants, our rural interviewees indicated that many villagers financially support relatives in urban areas, resulting in the phenomenon of reverse remittances. About one third of the families support urban-based members compared to only one fifth of the rural families who receive remittances. Moreover, 
$23 \%$ of the families exclusively give reverse remittances compared to just $6 \%$ who exclusively receive remittances. The higher frequency of reverse remittances is also matched by the total amount of money, about four times more money is given in reverse remittances than received. ${ }^{7}$

\section{Opportunities for Children and Young Adults}

The latent variable named 'child opportunities' is another (but less influential) variable of migration intention. While the largest share of respondents with a positive intention to move gave job-related reasons, about a third indicated that they want to improve the opportunities for their children. The individual input variables that are combined in this latent summary variable fall below the threshold of $0.5 \%$ variance reduction for the migration intention variable. However, when we look at the influence of individual input variables on this summary variable, we see that access to good schools and higher education facilities are the most influential single variables. As mentioned above, young people leaving for educational purposes is a serious issue in rural Kazakhstan (and elsewhere) as many of them will not return.

The variable ethnicity has a rather small but distinct influence on the "child opportunity' variable. We already pointed out that there are signs of discrimination against non-Kazakh ethnicities in the labour and housing market. Moreover, there are a multitude of policies related to nation building and the 'Kazakhification' of the country. ${ }^{8}$ To recall a few: (1) moving the capital from Almaty to Nursultan, (2) making Kazakh the official national language, and (3) increasing the share of ethnic Kazakhs in the administration to a level such that it is now dominated by ethnic Kazakhs (Bissenova 2017; Peyrouse 2007; Wolfel 2002). Not surprisingly, as a consequence, many ethnic Russians believe they do not have the same opportunities as ethnic Kazakhs (Laitin 1998) (see also results on 'assessment of the urban option'). Thus, only $16 \%$ of non-Kazakh respondents have a rural-urban migration intention, compared to $34 \%$ of the Kazakh respondents. While the Kazakhification process appears successful in urban areas, the effects on the countryside seem to be the opposite.

\section{Policy Scenarios}

We apply scenario analyses to a bundle of migration relevant policies, programmes, and regulations to assess their effects on the migration intentions of the rural population. Scenarios can be implemented in a Bayesian Network, e.g. by changing the

\footnotetext{
7 Of course some of these reverse remittances also cover expenses for higher education. However, only a third of the families sending reverse remittances are sending them to students.

8 The process of Kazakhification already began in the early 1990s (Kaiser and Chinn 1995). However, Kazakhification is not a formal policy objective. It is rather a process in which formal and informal policies/institutions intermingle (Kolst $\varnothing$ 1998). Overall, ethnic Kazakhs now exceed other ethnicities. In the north, however, they are still in the minority. In our sample, the majority of respondents is of Russian and European descent (Ukraine, Polish, or German), namely 56\%.
} 
probability distributions of single variables. The resulting change in the target variable's posterior probability distribution depicts the potential development of each scenario (Frayer et al. 2014) and is then compared to the initial states in the baseline model. As basis for our comparative institutional analysis, we develop three scenarios based on migration relevant policies, programmes, and regulations and information from the sensitivity and diagnostic analyses.

The first scenario focusses on the strategy of the City Planning Department of Nursultan, namely to drive housing prices up in order to deter rural-urban migration. We assume that the City Planning Department could further constrain the housing supply, which would further restrict affordable housing and consequently raise the living expenses in the city. As mentioned above, villagers often have an overly optimistic view of the urban job market. In this regard, targeted and accurate information on urban salaries and housing costs may help villagers to better evaluate the net cost/benefit from relocation. A better information base could work as a retain factor and thus working in favour of people to staying put. This is modelled by a reduction in the individual perception of improving one's living standard in the city.

The second scenario focuses on the rural side of the migration system, which means not only reducing the push-out factors of the countryside but also strengthening the retain factors. In the second scenario, we modify the perception variable regarding schooling facilities, including decentralised (closer to the rural home region) higher education facilities. Despite living in a high out-migration area, the norm for staying is still strong in Akmola. One third of the respondents agreed with the statement that people should stay close to the place they were born. Also, the majority of the respondents' peers oppose moving to the city. These norms and attitudes could be further encouraged by soft policies via a rural narrative, similar to the way the Kazakh government has influenced the narrative on nation building and Nursultan.

The third scenario combines the first and the second scenario. These three scenarios are compared against the initial state, which is described in the initial Bayesian Network (see Fig. 1). The results of the scenario analyses are presented in Table 4.

Changing the factors relevant for the migration intention solely on one side of a migration system, i.e. deterring urban migration (scenario 1) or supporting rural staying (scenario 2), can reduce migration intentions, but considering both sides has a bigger effect (scenario 3) and decreases the probability of having a migration intention by $15 \%$ points. On the rural sending side, changing narratives and related norms may have the biggest effect. However, influencing a narrative without physical change on the ground (such as improving the quality of rural schools) may be difficult to sell. On the urban receiving side, it may not be necessary to further exacerbate the distortion of the housing market. It may be simply enough to convey accurate information to the rural population about the urban housing market (rents/living costs) and job market (salaries), indicating that there is often a mismatch between both. 


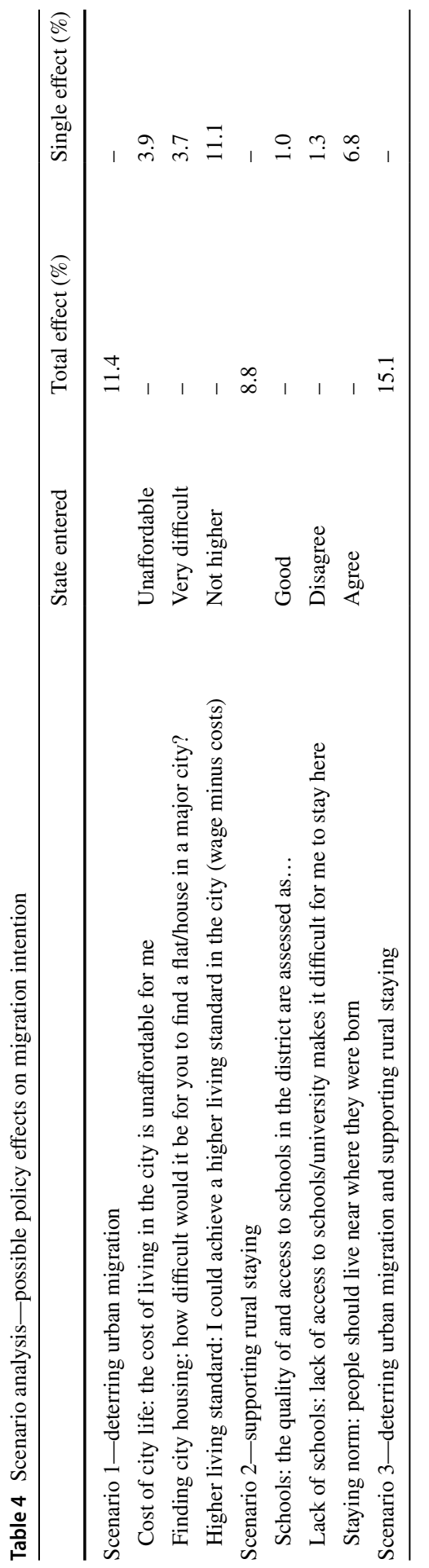




\section{Conclusion}

When many people leave rural areas, aggravated problems of underdevelopment can arise, while, in the urban destination, the provision of public goods may not keep pace with the influx of migrants. Hence, there is a public interest to influence the behaviour of people through policy interventions or regulations so that people voluntarily stay in the countryside. We apply Bayesian Networks to first analyse which factors influence rural-urban migration intentions of rural residents in northern Kazakhstan. Second, in a comparative institutional analysis, we model three scenarios in which we modify migration relevant exogenous and endogenous institutions to assess how this would change migration intentions.

Our analyses show that intensifying the repelling nature of the urban housing market may lower migratory pressure to some extent. However, this repelling effect is likely to be attenuated through urban social networks and financial support from relatives in the countryside (i.e. reverse remittances). In this sense, fast-moving institutions are out-manoeuvred by slow-moving endogenous institutions. Thus, rural areas are not only losing people but are also being drained of financial resources that otherwise may have been invested into the local economy-further reinforcing the vicious cycle of rural out-migration and underdevelopment. Providing rural residents with appropriate information on potential income and housing costs in urban areas may be a more promising road. This could improve the ability of potential migrants to more accurately assess whether or not the urban option would indeed provide them with a higher living standard. Thus, reduced expectations may prevent potential migrants from moving. This would also lessen the need for reverse remittances to support unsustainable livelihoods in urban areas.

The overall state of public goods in rural areas appears not to play a decisive role in the migration decision making process, except for schools and tertiary education. This may be related to the fact that the Kazakh government has invested in rural public goods over the last decade and has reached a sufficiently high level, at least to the point that it does not push people towards urban areas. To increase the intention to stay, instead of focussing on rural public goods in general, a much more promising approach would be to focus on schools and tertiary educational facilities. The Kazakh government has already begun to decentralise higher education facilities. Furthermore, it has set up special scholarship programmes to attract highly qualified professionals as state employees in rural areas. These scholarship programmes could be targeted to decentralised higher education facilities and thus further weaken the 'migrating-to-learn' - 'learning-to-migrate' chain.

Another regulatory adjustment could oblige people wanting to pursue a career in state agencies to serve a certain amount of time working in the countryside. Not 
only could this improve public services in rural areas but it would also send a signal that the government places importance on maintaining viable and attractive rural areas. Together with rural economic stimulus programmes, this could help to develop a positive narrative of rural and small-town economic areas and thus influencing slow-moving institutions. As shown in the literature review, the Kazakh government uses narratives to promote its goals. As a side note, we found indications of discrimination against non-Kazakh ethnicities in the urban job and housing market. Consequently, non-Kazakhs have considerably lower migration intentions than ethnic Kazakhs. Thus, for the rural countryside in northern Kazakhstan, the Kazakhification process has had the contrary effect-lowering the share of ethnic Kazakhs in the rural north.

Acknowledgements This article is a contribution to the project: 'New Institutionalism and Bayesian Networks: Establishing an analytical framework to model migration decision making in rural Kazakhstan' funded by the German Research Foundation DFG (BU1319/16-1, HE 5272/8-1). We would like to thank our research team in Kazakhstan Ms Aigerim Zhumakanova, Mr. Yerbolat Assylbek, Mr. David Runschke, and especially Prof. Dr. Galiya Sagyndykova from Nazarbayev University. Special thanks goes to pour colleague Dr. Judith Möllers for her very helpful comments.

\section{Compliance with Ethical Standards}

Conflict of interest On behalf of all authors, the corresponding author states that there is no conflict of interest.

Open Access This article is licensed under a Creative Commons Attribution 4.0 International License, which permits use, sharing, adaptation, distribution and reproduction in any medium or format, as long as you give appropriate credit to the original author(s) and the source, provide a link to the Creative Commons licence, and indicate if changes were made. The images or other third party material in this article are included in the article's Creative Commons licence, unless indicated otherwise in a credit line to the material. If material is not included in the article's Creative Commons licence and your intended use is not permitted by statutory regulation or exceeds the permitted use, you will need to obtain permission directly from the copyright holder. To view a copy of this licence, visit http://creativecommons.org/licen ses/by/4.0/.

\section{Appendix}

See Table 5 . 


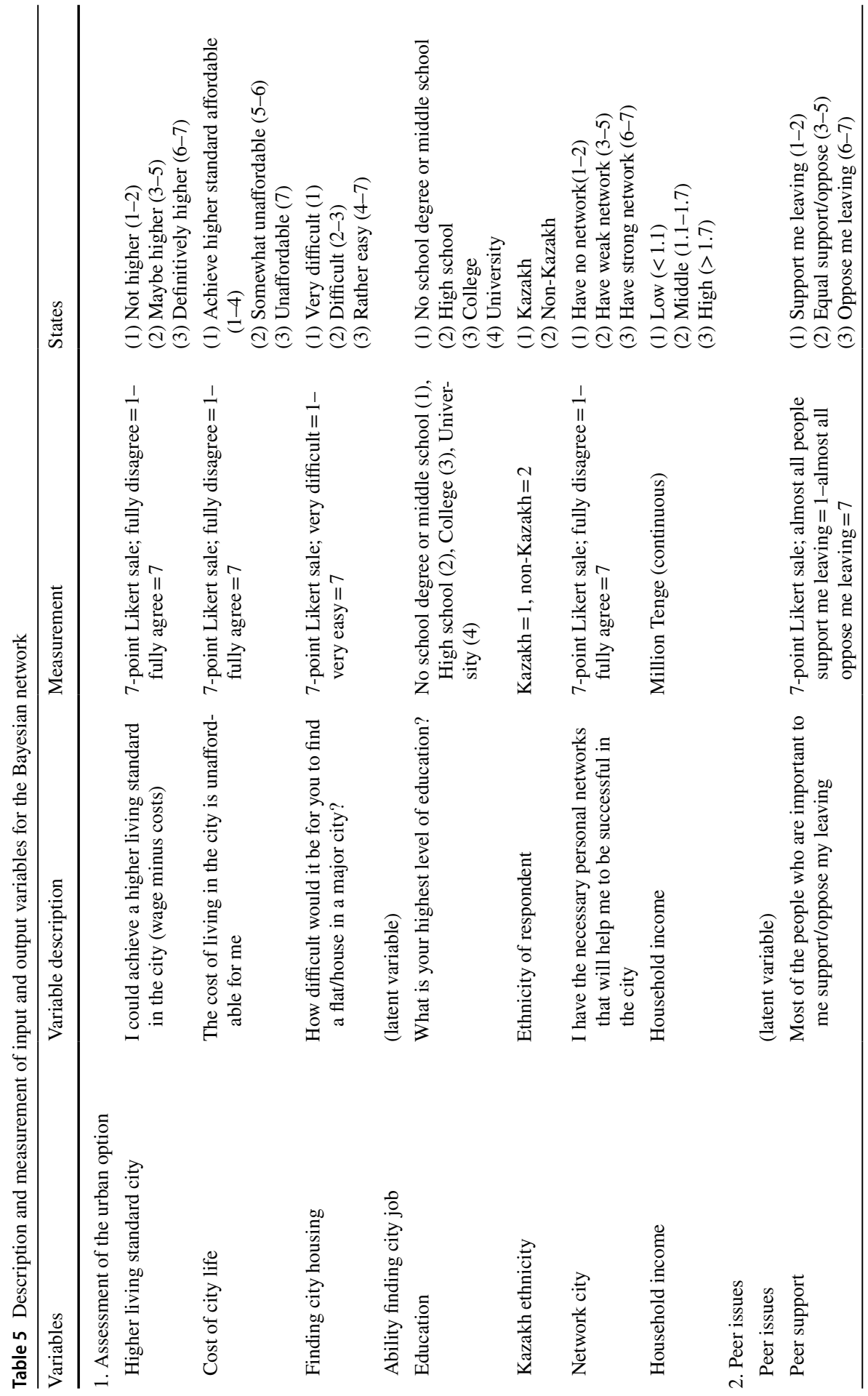




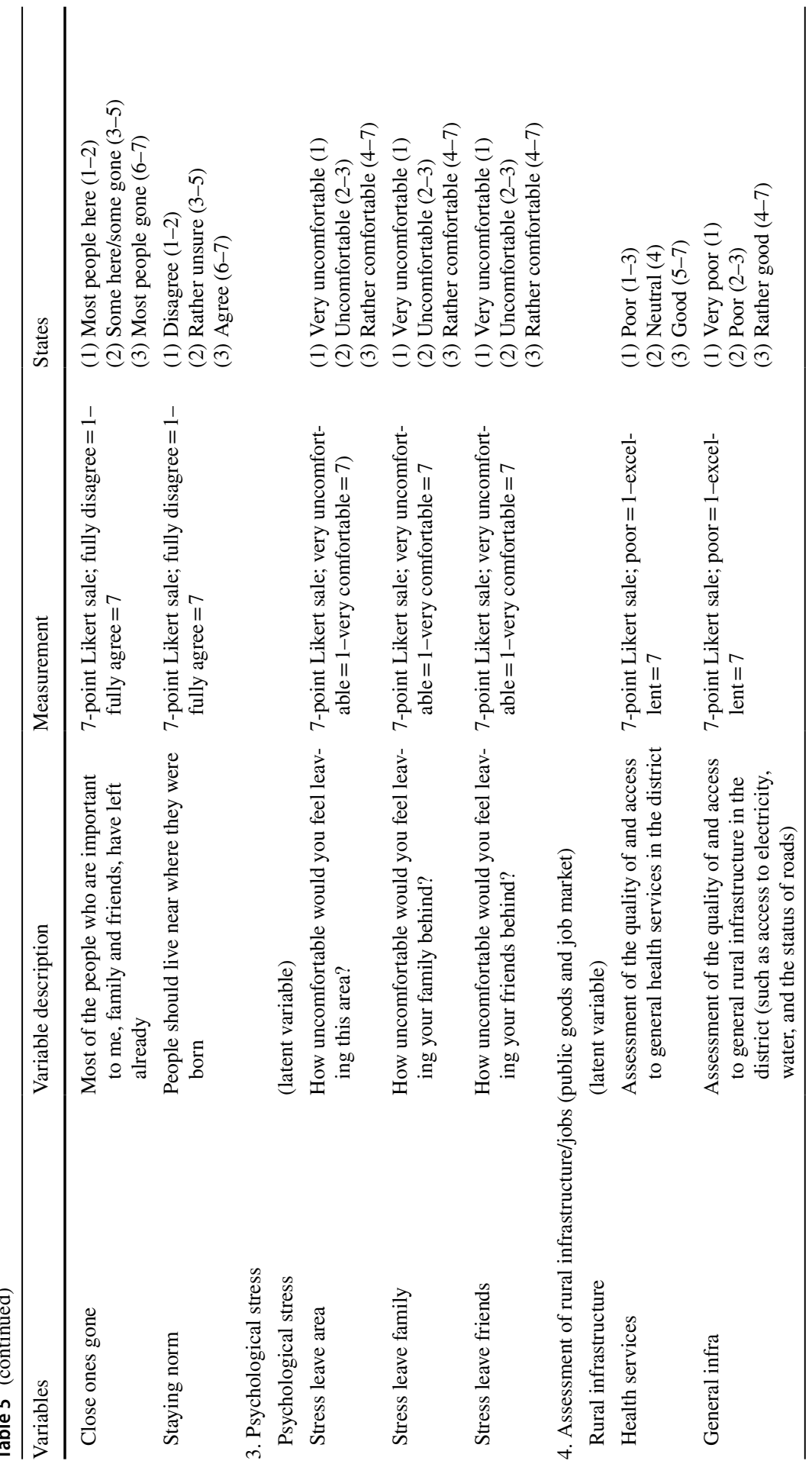




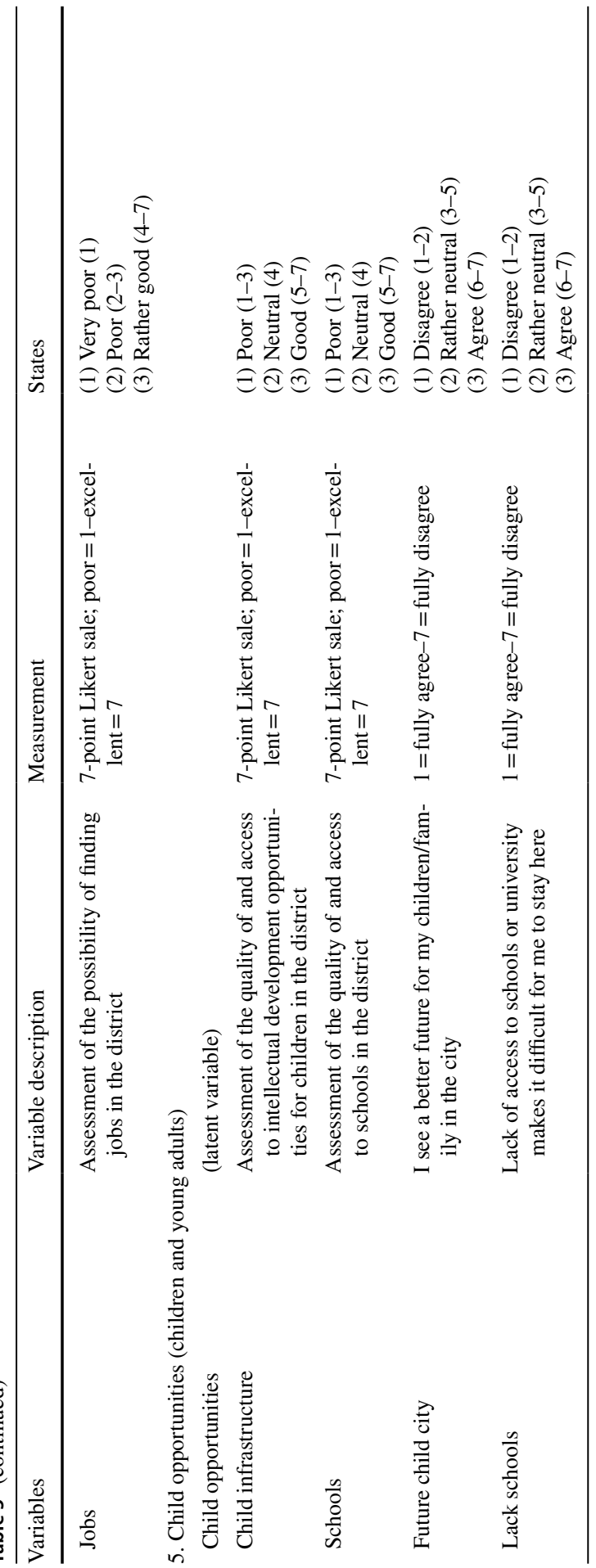

站 


\section{References}

Abdramanova, S. 2017. Ethnic identity of Kazakhstani young people in relation to language. Eurasian Journal of Philology: Science and Education 166 (2): 140-147.

Abraham, M., and N. Nisic. 2012. A simple mobility game for couples' migration decisions and some quasi-experimental evidence. Rationality and Society 24 (2): 168-197.

Aguilera, P.A., A. Fernandez, R. Fernandez, R. Rumi, and A. Salmeron. 2011. Bayesian networks in environmental modelling. Environmental Modelling \& Software 26 (12): 1376-1388.

Aitymbetov, N., E. Toktarov, and Y. Ormakhanova. 2015. Nation-building in Kazakhstan: Kazakh and Kazakhstani identities controversy. Bilig 74: 1-18.

Alesina, A., and P. Giuliano. 2010. The power of the family. Journal of Economic Growth 15 (2): 93-125.

Alexander, C., V. Buchli, and C. Humphrey. 2007. Introduction. In Urban life in post-Soviet Asia, ed. C. Alexander, V. Buchli, and C. Humphrey. London: UCL Press.

Alff, H. 2010. Zwischen geburtsort und land der vorväter: Die sozialen netzwerke von kasachen aus der mongolei und ihre rolle im postsowjetischen migrations-und inkorporationsprozess. Potsdam: Universität Potsdam.

An, G., C.M. Becker, and E. Cheng. 2017. Economic crisis, income gaps, uncertainty, and interregional migration responses: Kazakhstan 2000-2014. The Journal of Development Studies 53 (9): $1452-1470$.

Anacker, S. 2004. Geographies of power in Nazarbayev's Astana. Eurasian Geography and Economics 45 (7): 515-533.

Anderson, R.D., R.D. Mackoy, V.B. Thompson, and G. Harrell. 2004. A Bayesian network estimation of the service-profit chain for transport service satisfaction. Decision Sciences 35 (4): 665-689.

Anderson, R.D., and G. Vastag. 2004. Causal modeling alternatives in operations research: Overview and application. European Journal of Operational Research 156 (1): 92-109.

Arango, J. 2000. Explaining migration: A critical view. International Social Science Journal 52 (165): 283-296.

Beauchemin, C., and B. Schoumaker. 2005. Migration to cities in Burkina Faso: Does the level of development in sending areas matter? World Development 33 (July): 1129-1152.

Bissenova, A. 2017. The fortress and the frontier: Mobility, culture, and class in Almaty and Astana. Europe-Asia Studies 69 (4): 642-667.

Buchenrieder, G., T. Dufhues, J. Möllers, D. Runschke, and G. Sagyndykova. 2019. Return to the countryside: The return intentions of highly educated young people in the Akmola province of northern Kazakhstan. Population, Space and Place, in print.

Carling, J. 2002. Migration in the age of involuntary immobility: Theoretical reflections and Cape Verdean experiences. Journal of Ethnic and Migration Studies 28 (1): 5-42.

Carling, J., and K. Schewel. 2018. Revisiting aspiration and ability in international migration. Journal of Ethnic and Migration Studies 44 (6): 945-963.

Castles, S. 2004. The factors that make and unmake migration policies. International Migration Review 38 (3): 852-884.

Chen, S.H., and C.A. Pollino. 2012. Good practice in Bayesian network modelling. Environmental Modelling \& Software 37: 134-145.

Davis, K. 1988. Social science approaches to international migration. In Population and resources in Western intellectual traditions, ed. M.S. Teitelbaum and J.M. Winter, 245-261. Cambridge: Cambridge University Press.

De Brauw, A., V. Mueller, and H.L. Lee. 2014. The role of rural-urban migration in the structural transformation of Sub-Saharan Africa. World Development 63: 33-42.

de Haas, H. 2011. The determinants of international migration: Conceptualizing policy, origin and destination effects. IMI Working Papers (Vol. 32). Oxford: International Migration Institute (IMI), University of Oxford.

de Jong, G.F. 2000. Expectations, gender, and norms in migration decision-making. Population Studies 54 (3): 307-319.

Dietz, B., K. Gatskova, and A. Schmillen. 2011. Migration and remittances in Kazakhstan: First evidence from a household survey. Working Papers (Vol. 304). Regensburg, Germany: Osteuropa-Institut.

Emirbayer, M., and A. Mische. 1998. What is agency? American Journal of Sociology 103 (4): 962-1023. Frayer, J., Z. Sun, D. Müller, D.K. Munroe, and J. Xu. 2014. Analyzing the drivers of tree planting in Yunnan, China, with Bayesian networks. Land Use Policy 36: 248-258. 
GovReKaz. 2018. Employment for graduates, Russian translation. https://egov.kz. Astana: Government of the Republic of Kazakhstan (GovReKaz). Accessed September 2018.

Hofstede, G.H. 2001. Culture's consequences: Comparing values, behaviors, institutions, and organisations across nations. Thousand Oaks: Sage Publications.

Hollifield, J.F. 2008. The politics of international migration how can "we bring the state back In"? In Migration theory, ed. C.B. Brettell and J.F. Hollifield, 183-238. New York: Routledge.

Jaeger, D.A., T. Dohmen, A. Falk, D. Huffman, U. Sunde, and H. Bonin. 2010. Direct evidence on risk attitudes and migration. The Review of Economics and Statistics 92 (3): 684-689.

Jensen, F.V. 2001. Bayesian networks decision graphs. New York: Springer.

Kaiser, R., and J. Chinn. 1995. Russian-Kazakh relations in Kazakhstan. Post-Soviet Geography 36 (5): $257-273$.

Kjaerulff, U.B., and A.L. Madsen. 2013. Bayesian networks and influence diagrams: A guide to construction and analysis. New York: Springer.

Kolstø, P. 1998. Anticipating demographic superiority: Kazakh thinking on integration and nation building. Europe-Asia Studies 50 (1): 51-69.

Laitin, D.D. 1998. Identity in formation: The Russian-speaking populations in the near abroad. Ithaca: Cornell University Press.

Lee, E.S. 1966. A theory of migration. Demography 3 (1): 47-57.

Marcot, B.G. 2012. Metrics for evaluating performance and uncertainty of Bayesian network models. Ecological modelling 230: 50-62.

Marcot, B.G., J.D. Steventon, G.D. Sutherland, and R.K. McCann. 2006. Guidelines for developing and updating Bayesian belief networks applied to ecological modeling and conservation. Canadian Journal of Forest Research 36 (12): 3063-3074.

Massey, D.S., J. Arango, G. Hugo, A. Kouaouci, and A. Pellegrino. 1998. Worlds in motion: Understanding international migration at the end of the millennium. Oxford: Oxford University Press.

OECD. 2007. Reviews of national policies for education: Higher education in Kazakhstan. Paris: OECD.

OECD. 2017. OECD urban policy reviews: Kazakhstan. Paris: OECD.

Osmonova, K. 2016. Experiencing liminality: Housing, renting and informal tenants in Astana. Central Asian Survey 35 (2): 237-256.

Petrick, M., J. Wandel, and K. Karsten. 2013. Rediscovering the virgin lands: Agricultural investment and rural livelihoods in a Eurasian frontier area. World Development 43: 164-179.

Peyrouse, S. 2007. Nationhood and the minority question in Central Asia. The Russians in Kazakhstan. Europe-Asia Studies 59 (3): 481-501.

Pollino, C.A., O. Woodberry, A. Nicholson, K. Korb, and B.T. Hart. 2007. Parameterisation and evaluation of a Bayesian network for use in an ecological risk assessment. Environmental Modelling \& Software 22 (8): 1140-1152.

Rérat, P. 2016. Migration and post-university transition. Why do university graduates not return to their rural home region? Geographica Helvetica 71 (4): 271.

Roland, G. 2004. Understanding institutional change: Fast-moving and slow-moving institutions. Studies in Comparative International Development 38 (4): 109-131.

Schatz, E. 2000. The politics of multiple identities: Lineage and ethnicity in Kazakhstan. Europe-Asia Studies 52 (3): 489-506.

Schewel, K. 2015. Understanding the aspiration to stay: A case study of young adults in Senegal. Oxford: International Migration Institute.

Schewel, K. 2019. Understanding immobility: Moving beyond the mobility bias in migration studies. International Migration Review, in print, 1-28.

Taylor, J.E., and P.L. Martin. 2001. Human capital: Migration and rural population change. In Handbook of agricultural economics, ed. B.L. Gardner and G.C. Rausser, 457-511. New York: Elsevier Science.

Thissen, F., J.D. Fortuijn, D. Strijker, and T. Haartsen. 2010. Migration intentions of rural youth in the Westhoek, Flanders, Belgium and the Veenkoloniën, The Netherlands. Journal of Rural Studies 26 (4): 428-436.

Tiwari, S. 2017. Does local development influence outmigration decisions? Evidence from Indonesia. World Development 93: 108-124.

Todaro, M.P. 1969. A model of labor migration and urban unemployment in less developed countries. American Economic Review 59 (1): 138-148.

Toleubayev, K., K. Jansen, and A. van Huis. 2010. Knowledge and agrarian de-collectivisation in Kazakhstan. The Journal of Peasant Studies 37 (2): 353-377. 
Wolfel, R.L. 2002. North to Astana: Nationalistic motives for the movement of the Kazakh(stani) capital. Nationalities Papers 30 (3): 485-506.

Yan, X., S. Bauer, and X. Huo. 2014. Farm size, land reallocation, and labour migration in rural China. Population, Space and Place 20 (4): 303-315.

Zorrilla, P., G. Carmona, A. De la Hera, C. Varela-Ortega, P. Martinez-Santos, J. Bromley, and H.J. Henriksen. 2010. Evaluation of Bayesian networks in participatory water resources management, Upper Guadiana basin, Spain. Ecology and Society 15 (3): 26268156.

Publisher's Note Springer Nature remains neutral with regard to jurisdictional claims in published maps and institutional affiliations. 